\title{
The risk of reconstruction failure following a mastectomy, breast reconstruction and radiotherapy depending on the reconstruction technique
}

\author{
Anna Niwińska
}

Department of Breast Cancer and Reconstructive Surgery, Maria Sklodowska-Curie National Research Institute of Oncology, Warsaw, Poland

Improvements in the recently observed breast reconstruction surgery techniques have changed the clinical practice in patients with breast cancer. Nowadays, every patient diagnosed with breast cancer clinical stage I, II and III, except for inflammatory breast cancer, should have the opportunity to undergo breast reconstruction. Radiation therapy increases the risk of complications following reconstruction. The aim of this paper is to review the current literature in an attempt to select the safest and most convenient reconstruction technique in patients requiring radiation therapy. Immediate autologous breast reconstruction seems to be the best option, but everyday clinical practice seems to contradict the conclusions from these data. The choice of the reconstruction type depends not only on the rate of complications but on the surgeon's skills, the patient's preference and the hospital's equipment.

Key words: breast cancer, breast reconstruction, implant reconstruction, pre-pectoral reconstruction, subcutaneous implant reconstruction

\section{Introduction}

Some years ago, candidates for immediate reconstruction following a subcutaneous mastectomy were patients with breast cancer in its early stages, in cases where it was probable that adjuvant radiotherapy would not be necessary. This applied to situations when breast conserving therapy was not possible (numerous suspicious micro-calcifications, multifocal cancer, extensive pre-invasive cancer). Patients with more advanced stages of the disease underwent delayed reconstructions, usually at least 1 year after the completion of radiation [1]. Recent years have brought significant changes in the approach to post-mastectomy breast reconstruction.

Firstly, according to the guidelines proposed by academic societies and expert panels of leading conferences, every woman after a mastectomy, should be given the possibility of undergoing breast reconstruction, whilst immediate reconstruction, made at the same time as oncological intervention, can be performed in patients with breast cancer at clinical stage I, II and III, except for the cases of inflammatory breast cancer [2-4]. This means that the majority of patients after mastectomy and immediate reconstruction may require further adjuvant irradiation.

Secondly, together with significant progress in reconstruction surgeries consisting of the introduction of synthetic meshes and acellular skin matrices of animal origin, a significant increase in the rate of immediate reconstructions can be currently observed - especially with regards to those implanted subcutaneously (prepectoral breast reconstruction),

\section{How to cite:}

Niwińska A. The risk of reconstruction failure following a mastectomy, breast reconstruction and radiotherapy depending on the reconstruction technique. NOWOTWORY J Oncol 2021; 71: 373-382. 
while there is a decrease in the number of reconstructions with the use of the patient's native tissues [5-12]. Nowadays, in some European centres (Switzerland, Germany), the rate of prepectoral breast reconstructions varies between 65\% and $80 \%$ and more (Sweden, Austria) [5]. This new approach toward patients who require radiotherapy and also short follow-up periods after reconstruction, following new techniques with irradiation, presents a large challenge for radiotherapists and encourages doctors to systematize knowledge in this field and to work out an optimum strategy of action.

The objective of the work is to present a literature overview concerning the types and frequency of complications after various types of breast reconstruction and radiotherapy.

\section{Basic definitions concerning breast reconstruction}

Breast reconstructions may be divided with respect to the type of material used and also with regards to the time of surgery as compared to basic oncological surgery (Fig. 1 and 2). With regards to the material used, the reconstructions can be divided into autologous types, made from the patient's own tissues and alloplastic (implant-based) - made from synthetic materials. Autologous reconstructions employ musculocu-

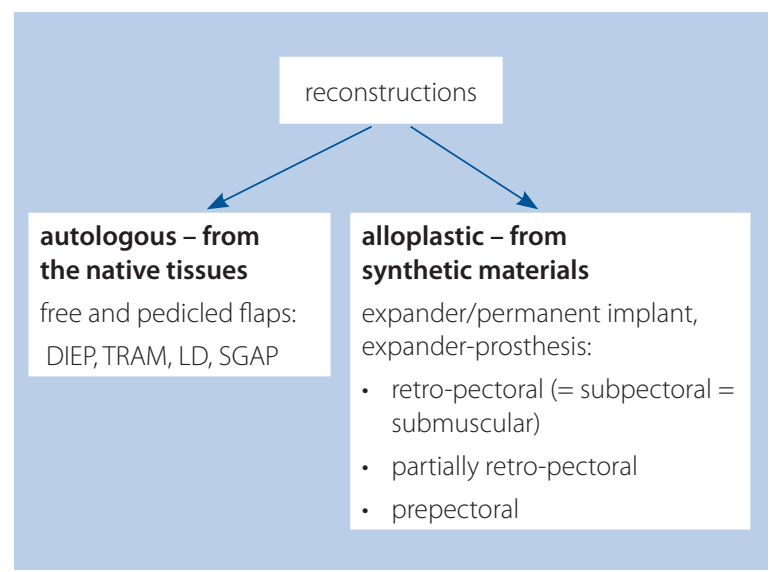

Figure 1. Types of breast reconstructions depending on the type of material used taneous pedicled or free flaps, which require microvascular anastomoses. The most frequently used flaps comprise DIEP (deep inferior epigastric artery perforator free flap), TRAM (transverse rectus abdominis musculocutaneous pedicled flap), LD (latissimus dorsi musculocutaneous pedicled flap) and SGAP (gluteal musculocutaneous free flap) [13-18]. Autologous reconstructions comprise also autologous fat grafting.

Alloplastic reconstructions consist of the implantation of a prosthesis (implant). This can be a permanent implant (permanent prosthesis), an expander or an expander-prosthesis. An expander is used for expanding tissues before the final implanting of a breast prosthesis, so it requires exchange into a permanent implant after a previous filling the bed and expanding the skin and major pectoral muscle. A permanent implant may be located underneath both the pectoral and serratus anterior muscles (subpectoral, postpectoral and submuscular reconstruction), underneath the pectoral and on the surface of the serratus anterior muscle (partly postpectoral and submuscular reconstruction) or underneath the skin, onto the surface of the pectoral muscle (prepectoral reconstruction). In the majority of cases of partly subpectoral reconstruction and in all cases of prepectoral reconstruction, the implant is covered with a synthetic mesh (SM) or with an acellular dermal matrix (ADM) of animal origin.

As for as the time interval between oncological surgery (various types of mastectomies) and breast reconstruction, the intervention types can be divided into immediate and delayed. Immediate reconstruction is performed at the same time as oncological intervention. If the permanent implant is placed at once (prosthesis, expander-prosthesis), such a reconstruction is called an immediate one-stage breast reconstruction. If an expander is placed in the first stage following the mastectomy, and then, once the expander extends after a few weeks, it is exchanged into a permanent prosthesis or an autologous reconstruction is performed, such a procedure is named a delayed immediate breast reconstruction or immediate twostage breast reconstruction.

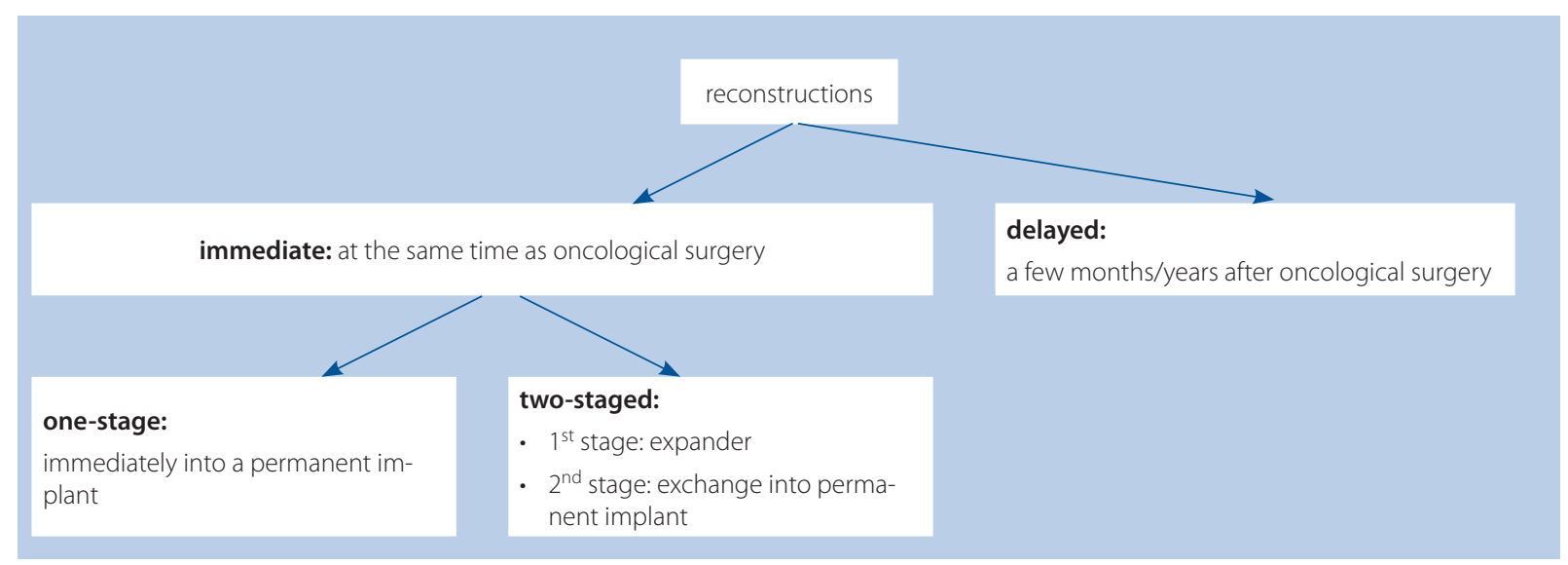

Figure 2. Types of breast reconstructions with regards to the time interval between the oncological surgery and the reconstruction 
Delayed breast reconstruction is performed a few months or even years after the initial oncological surgery. The optimum time interval between the end of radiotherapy and the date of delayed reconstruction is not known [19], yet it seems that it should be at least 12 months after radiation therapy [1].

\section{The type and rate of complications following reconstruction and radiotherapy}

Breast reconstruction with or without radiotherapy, may be followed by complications such as hematoma, seroma, infection, rippling, fat necrosis, skin necrosis, expander displacement, expander exposure or rupture, fibrosis around the prosthesis or the expander, implant loss, fibrosis or loss of the musculocutaneous flap. In the literature on the subject, presentation of the risk of complications following breast reconstruction with/without radiotherapy is divided into general risk of complications and the risk of serious complications. The overall complications comprise at least one complication [20]. A serious complication is defined as a complication which requires hospitalisation and/or surgery. The most serious complication i.e. reconstruction failure, is implant loss or necrosis and the loss of the musculocutaneous flap [20].

Radiotherapy increases the risk of complications [1, 13, 14, 20-33]. The subject literature reports that the reconstruction failure rate after radiotherapy is 6-62.6\% [30]. The first study concerned radiotherapy following immediate reconstruction with an implant, with a 10-year follow-up period. It reported the risk of complications in general to be $52.5 \%$ after radiotherapy and $10 \%$ without radiotherapy, whilst capsule fibrosis was observed in $32.5 \%$ after irradiation vs. $0 \%$ without irradiation [34]. The analyses published in the following years confirm that radiotherapy increased the risk of complications to 55\% [17-25] and the risk of implant loss to 4.8\%-37\% [20, 22-24, 35-38].

Below, we present the types of complications following specific types of reconstruction with radiotherapy, together with the degree of risk.

\section{Alloplastic (implant-based) breast reconstruction with radiation therapy}

The meta-analysis presented by Pu et al. [39] which examined 15 studies contained a calculation of the complication rate following immediate one stage reconstruction with an implant, with and without radiotherapy (4245 and 1069 patients respectively). It was shown that radiotherapy increased the risk of complications in general more than threefold (odds ratio $[O R]=3.45)$, the risk of implant loss - more than twofold (OR $=2.6$ ) and the risk of capsule fibrosis around the implant more than fivefold $(O R=5.3)$. Moreover, radiotherapy decreased patient satisfaction with the procedure by a factor of four in comparison with patients who were not irradiated $(O R=0.28)$ [39]. The meta-analysis presented by Hong et al. [40] referred to a group of 6757 patients, and 13 out of the 19 presented studies concerned an immediate, two-stage reconstruction (expander $->$ radiotherapy $->$ exchange into a permanent implant). The meta-analysis showed that radiotherapy increased the risk of complications in general more than twofold $(\mathrm{OR}=2.52)$, the implant loss - more than twofold $(\mathrm{OR}=2.57)$, whilst the risk of capsule fibrosis around the implant - was almost sixfold $(O R=5.99)$, which was connected with a decrease in patient satisfaction $(O R=0.29)$ and a poorer aesthetic effect $(O R=0.25)$ [40]. The meta-analysis presented by Ricci et al. [23] compared the complications following immediate reconstruction with radiotherapy with an expander and immediate reconstruction with radiotherapy with a permanent implant. The analysis of the histories of 2348 patients from 20 studies showed a high complication risk in both groups. In the group of patients after reconstruction and radiotherapy with an expander, more cases of implant loss were observed (20\% after radiotherapy with expander vs. 13.4\% after radiotherapy with a permanent implant; relative risk $[R R]=2.33$ ), whilst in the group after reconstruction and radiotherapy with a permanent implant, more cases of the fibrosis of the capsule around the implant were seen (49.4\% after radiotherapy with a permanent implant vs. 24\% after radiotherapy with expander) [23].

\section{Comparison of alloplastic prepectoral breast reconstructions with alloplastic subpectoral breast reconstructions with and without radiotherapy}

According to some publications, in patients without radiotherapy, immediate prepectoral reconstruction is comparable to subpectoral with regards to the rate of complications in general, the implant loss, the necrosis of the nipple/skin, poor wound healing and infections $[6,41]$. In the meta-analysis of Li et al. [41], the risk of implant loss after prepectoral and subpectoral reconstructions without radiotherapy was $4.2 \%$ and $4.5 \%$ respectively. In the meta-analysis of Abbate et al. [42], about $80 \%$ of 4040 patients were not irradiated. It was found that there were statistically significant differences concerning the rate of skin necrosis ( $3.3 \%$ vs. $5.9 \%, p<0.01$ ) and fibrosis of the skin around the implant ( $4.2 \%$ vs. $7.6 \%, p<0.01$ ) which worked to the advantage of prepectoral reconstruction. Apart from this, the rate of complications in the group of prepectoral and subpectoral surgeries was comparable. It must be observed that the complication rate following reconstructions in both groups without radiotherapy was lower than 10\%.

Radiotherapy increased the complication rate, whilst the risk varied depending on the type of reconstruction [1 1,43-45]. In a prospective study evaluating the risk of complications in patients after prepectoral reconstruction, with and without radiotherapy, it was found that the patient group after radiotherapy had a seven-fold higher risk of complication in general $(O R=7.11)$ and five-fold higher risk of implant loss $(\mathrm{OR}=5.09)$ in comparison with patients who were not irradiated [45]. The work of Sinnot et al. [10] contained an analysis of the complication rate following prepectoral and subpec- 
toral reconstructions with and without radiotherapy. A higher complication rate was found in the group after radiotherapy. In a group of 274 patients after prepectoral reconstruction and radiotherapy, in $16 \%$ of the cases fibroses around the implant were observed, whilst in the group of 100 patents after a subpectoral reconstruction and radiotherapy, this rate was 52\% [10]. In the study of Thuman et al. [11], the risk of implant loss following prepectoral reconstruction and radiotherapy was $4.5 \%$, whereas following a subpectoral reconstruction and radiotherapy, it was $14.9 \%$.

The results illustrate that in patients after an immediate alloplastic reconstruction with radiotherapy, irrespective of the reconstruction type (prepectoral vs. subpectoral), the risk of complications is high, yet it seems that prepectoral reconstruction is safer $[8,10,11]$. In order to confirm the higher level of safety in prepectoral reconstruction with radiotherapy over subpectoral reconstruction with radiotherapy, it is necessary to have a longer follow-up period in patients after prepectoral reconstructions; in the majority of publications the median follow-up period is about 2 years.

\section{Comparison of alloplastic breast reconstructions and radiotherapy with autologous breast reconstructions and radiotherapy}

Breast reconstruction with prostheses followed by radiotherapy give more complications than autologous reconstruction with radiotherapy $[1,13,44-56]$. The meta-analysis conducted by Barry [47] compared various types of breast reconstruction (immediate and delayed, with implants and autologous) with and without radiotherapy on the basis of 11 studies and 1105 patients. In patients after immediate reconstruction with a prosthesis/expander without radiotherapy, the rate of complications in general was $21 \%$ and in patients after radiotherapy - 52\%. In irradiated patients, immediate autologous reconstruction was five times safer than alloplastic reconstruction ( $O R=0.21)$. Immediate autologous reconstruction with radiotherapy and delayed autologous reconstruction following radiotherapy were comparable with respect to complications $(\mathrm{OR}=0.87)$ [47].

The objective of the meta-analysis made by O'Donell et al. [48], made on the basis of 16 studies and 2322 reconstructions, was to see what the optimum type of breast reconstruction was for women who had to be irradiated, especially, with respect to the most serious complications. Six groups of patients were analysed: those after immediate autologous breast reconstruction with radiotherapy, those after delayed immediate breast reconstruction with radiation therapy to an expander, those after delayed immediate breast reconstruction with radiation therapy to the permanent implant, those after delayed immediate reconstruction with radiation therapy to an expander and final autologous breast reconstruction and also those after 2 types of delayed reconstructions following radiotherapy: delayed autologous and delayed alloplastic breast reconstruction. The best procedure, which prevented or at least decreased the risk of reconstruction failure in irradiated patients, was an immediate autologous reconstruction. This method was better than all the reconstructions with implants. Among alloplastic reconstructions in turn, the most beneficial was the procedure of radiotherapy applied onto the permanent implant: in these cases the rate of complications in general was three times lower $(\mathrm{OR}=0.35)$, yet also there were twice as many fibroses around the implant $(\mathrm{OR}=2.58)$. The worst results were observed in patients who had radiotherapy during the primary oncological treatment and then underwent delayed reconstruction with an implant. The conclusions of the paper contain a note in which the authors observed that immediate reconstruction with the patient's native tissues, in patients who are scheduled for irradiation afterwards, was the best choice from the point of view of complications, however, the choice of the reconstruction method depends on the patient herself, the surgeon and the technical possibilities of the institution. If a patient who requires radiotherapy does not consent to reconstruction with her native tissues, and opts solely for a reconstruction with an implant, she should be proposed an immediate and non-delayed reconstruction [48].

The study of Jagsi et al. [53] compared the rate of complications after 2 years of follow-up in 2247 patients after an immediate reconstruction with an implant with and without radiotherapy and after an immediate autologous reconstruction with and without radiotherapy. The study showed that at least 1 complication, serious complication and the loss of the expander was significantly higher in patients undergoing radiotherapy in comparison to those not irradiated, irrespective of the reconstruction technique. At the same time, it was shown that in the group of irradiated patients, the rate of failures was significantly higher after implant-based reconstruction than in the group with an autologous reconstruction. The risk of implant loss in patients after implant-based reconstruction was $18.7 \%$ and after autologous reconstruction - 1\% [53]. Similarly, in other articles, a high rate of implant loss was shown (18.7-37\%) following immediate implant-based reconstructions and radiotherapy as well as a low rate of the loss of musculocutaneous flap (0-4.4\%) after immediate autologous reconstructions and radiotherapy [51, 52, 54-56].

A study performed by Chetta et al. [52], analysed 4781 irradiated patients, and the rate of reconstructions with implants in comparison to the autologous reconstructions made in 2009-2012 was 80\%. The risk of implant/flap loss after immediate alloplastic and immediate autologous reconstructions was $27 \%$ and $4 \%$, respectively, and after delayed alloplastic and delayed autologous reconstructions it was 37\% and 5\%, respectively. The authors summed up that in patients who required irradiation, reconstruction with implants as the most popular method of breast reconstruction was burdened with the risk of serious complications [52]. 


\section{Comparison of immediate autologous reconstructions followed by radiotherapy and delayed autologous reconstructions (after radiotherapy)}

The research shows that there are no significant differences in the rate of complications in patients after autologous reconstructions (either immediate or delayed) $[1,57,58]$. The meta-analysis made by Hershenhouse et al. [57], based on 44 studies, analysed the history of 1927 patients after immediate autologous reconstructions with radiotherapy and 1546 after delayed autologous reconstructions with radiotherapy. The rate of early complications was assessed, comprising fat necrosis, thrombosis, seroma, hematoma, infections, dehiscence of the wound edges, loss of the flap; and delayed complications: fibrosis, significant asymmetry, hyperpigmentation, volume decrease of the musculocutaneous flap. A comparable rate of complications was observed with the exception of the risk of seroma which was more frequent in the case of delayed reconstructions (2.6\% after immediate reconstruction and 10.5\% after delayed reconstruction, $p=0.04)$. Both methods were regarded as comparable with regards to the risk of complications and the risk of flap loss in both groups was lower than 2\%.

The meta-analysis of Heiman et al. [58] also compared the rate of complications after the reconstructions with native tissues: immediate with radiotherapy (729 patients) and delayed with radiotherapy (868 patients). It was shown that the risk of complete flap loss (2.4\% vs. 0.9\%, $p=0.004)$ or partial flap loss ( $4.6 \%$ vs. $1.9 \%, p=0.01$ ) was slightly higher after a delayed autologous reconstruction whilst the risk of infections - after immediate autologous reconstructions. The risk of other complications was comparable. The authors did conclude though that an immediate autologous reconstruction is more beneficial for tissue survival than delayed autologous reconstruction. That is why it should be proposed to patients who require radiotherapy [58].

\section{An evaluation of patient satisfaction following various types of reconstruction}

The BREAST-Q and BODY-Q questionnaires allow for an evaluation of patient satisfaction after breast reconstruction procedures as well as satisfaction with their psychosocial and sexual life, an evaluation of the physical appearance of the breasts and of the donor site of the musculocutaneous flap as well as satisfaction in general. In 6 papers, [53, 55, 59-62] the patient satisfaction was studied with regards to the quality of life and aesthetic effects following various types of breast reconstruction. In all the studies, better results were observed in patient opinion after autologous breast reconstructions.

\section{The best type of breast reconstruction with regards to the risk of complications in irradiated patients - analyses results}

The analyses presented above point to the fact that from the point of view of the risk of complications, the most be- neficial reconstruction for a patient requiring radiotherapy is immediate autologous breast reconstruction, whilst a delayed autologous breast reconstruction (i.e. performed a few months /years following primary oncological treatment with radiotherapy) ranks second. A significantly larger number of complications occur after immediate alloplastic reconstructions with radiotherapy onto the permanent implant, whilst immediate alloplastic reconstruction with radiotherapy onto the expander seems even less beneficial (it gives fewer fibrosis but a higher risk of implant loss than radiotherapy into the permanent implant). Prepectoral reconstructions with radiotherapy give slightly fewer complications than subpectoral reconstructions with radiotherapy. The highest risk of complications is observed after delayed reconstructions with implants and therefore this method is not recommended in breast cancer patients after pervious radiotherapy.

Tables I and II present the risk of reconstruction failure (RF), defined as the loss of the implant or the musculocutaneous flap, depending on the type of breast reconstruction in patients undergoing radiotherapy. The RF rate following immediate autologous reconstruction and radiotherapy varies $0-4.4 \%$, and following delayed autologous reconstruction (after previous irradiation) - 1.8-7\%; following immediate implant-based reconstruction and radiotherapy $-4.5-37 \%$; and following a delayed implant-based reconstruction (after previous irradiation) - 37-56\%.

\section{Why does clinical practice differ from the results of the studies? The advantages and disadvantages of autologous and alloplastic reconstructions}

In 2021 a panel of Italian experts published current data concerning breast reconstruction and radiotherapy (Italian Expert Delphi Consensus Statement) [19]. It confirmed that in patients requiring radiotherapy, the lowest complication rate and the best cosmetic effect is observed following an immediate autologous reconstruction. Contrary to these findings, implant based reconstruction (one-stage or two-staged) is the most frequently method used in this patient group [19].

Why do oncological centres in the majority of cases perform an implant reconstruction if radiotherapy is planned in spite of scientific evidence pointing to a lower risk of complications following autologous reconstructions? This is especially the case since autologous reconstructions keep evolving significantly, and together with progress in microsurgery, this allows for a further decrease in the complication rate in the donor site and reconstruction area [15]. It seems that as much as the rate of complications influences the type of reconstruction planning, the final decision depends also on other factors, such as the preferences of the surgeon concerning the treatment technique, the patient's preferences with respect to the method and her approval of a higher risk for a selected method, the possibilities of complex plastic surgeries in 
Table I. The risk of reconstruction failure in irradiated patients depending on the type of reconstruction

\begin{tabular}{|c|c|c|c|}
\hline $\begin{array}{l}\text { Individual original papers and } \\
\text { metanalyses }\end{array}$ & $\begin{array}{l}\text { The number of irradiated } \\
\text { patients }\end{array}$ & $\begin{array}{l}\text { Type of reconstruction with } \\
\text { irradiation, treatment sequence }\end{array}$ & The rate of implant / flap loss \\
\hline Tanos G. [51] & 114 & $\begin{array}{l}\text { immediate: } \\
\text { - } T E / I->R T \\
\text { - } \quad A R->R T\end{array}$ & $\begin{array}{c}37 \% \\
0\end{array}$ \\
\hline Chetta M.D. [52] & 4781 & $\begin{array}{l}\text { immediate: } \\
\text { - } T E / I->R T \\
\text { - } \quad \text { AR } \rightarrow \text { RT } \\
\text { delayed: } \\
\text { - } \quad R T->T E / I \\
\text { - } \quad R T \rightarrow A R\end{array}$ & $\begin{array}{c}27 \% \\
4 \% \\
\\
37 \% \\
5 \%\end{array}$ \\
\hline Jagsi R. [53] & $2247(482 \mathrm{RT})$ & $\begin{array}{l}\text { immediate: } \\
\text { - } T E / I->R T \\
\text { - } \quad A R \rightarrow R T\end{array}$ & $\begin{array}{l}18.7 \% \\
1 \%\end{array}$ \\
\hline Manyam B.V. [54] & 204 & $\begin{array}{l}\text { immediate: } \\
\text { - } \quad \text { AR }>\text { RT } \\
\text { - } \quad T E / I->R T \\
\text { delayed: } \\
\text { - } \quad R T->A R \\
\text { - } \quad R T->T E / l\end{array}$ & $\begin{array}{l}4.4 \% \\
22 \% \\
7 \% \\
56 \%\end{array}$ \\
\hline Reinders F.C.J. [55] & 109 & $\begin{array}{l}\text { immediate: } \\
\text { - } T E / I->R T \\
\text { - } A R \rightarrow R T\end{array}$ & $\begin{array}{c}21.3 \% \\
0\end{array}$ \\
\hline Naoum G.E. [56] & $1286(407 \mathrm{RT})$ & $\begin{array}{l}\text { immediate: } \\
\text { • } \quad T E->R T->\mid \\
\text { - I->RT }\end{array}$ & $\begin{array}{l}9.1 \% \\
2.9 \%\end{array}$ \\
\hline Thuman J.M. [11] & $\begin{array}{l}44 \\
141\end{array}$ & $\begin{array}{l}\text { immediate: } \\
\text { • TE/I ->RT } \\
\text { prepectoral } \\
\text { subpectoral }\end{array}$ & $\begin{array}{l}4.5 \% \\
14.9 \%\end{array}$ \\
\hline $\begin{array}{l}\text { metanalysis } \\
\text { Ricci J.A. [23] }\end{array}$ & $\begin{array}{l}1479 \\
869\end{array}$ & $\begin{array}{l}\text { immediate: } \\
\text { • } T E->R T->\mid \\
\text { - } T E->\mid>R T\end{array}$ & $\begin{array}{c}20 \% \\
13.4 \%\end{array}$ \\
\hline $\begin{array}{l}\text { metanalysis } \\
\text { Heiman A.J. [58] }\end{array}$ & $\begin{array}{l}729 \\
868\end{array}$ & $\begin{array}{l}\text { immediate: } \\
\text { - } \quad \text { AR } \rightarrow \text { RT } \\
\text { delayed: } \\
\text { - } \quad \text { RT -> AR }\end{array}$ & $\begin{array}{l}0.9 \% \\
2.4 \%\end{array}$ \\
\hline $\begin{array}{l}\text { metanalysis } \\
\text { Hershenhouse K.S. [57] }\end{array}$ & $\begin{array}{l}1927 \\
1546\end{array}$ & $\begin{array}{l}\text { immediate: } \\
\text { - } A R \rightarrow R T \\
\text { delayed: } \\
\text { - } \quad R T \rightarrow A R\end{array}$ & $\begin{array}{l}1 \% \\
1.8 \%\end{array}$ \\
\hline $\begin{array}{l}\text { metanalysis } \\
\text { O'Donnell J.P.M. [48] }\end{array}$ & 1914 & $\begin{array}{l}\text { immediate: } \\
\text { - } T E->R T->\mid \\
\text { - } T E->\mid->R T \\
\text { - } T E->R T->A R \\
\text { - } \quad A R \rightarrow R T \\
\text { delayed: } \\
\text { - } R T->A R \\
\text { - } R T \rightarrow T E \rightarrow \mid\end{array}$ & $\begin{array}{c}O R=1 \\
O R=0.42 \\
O R=0.27 \\
O R=0.1 \\
O R=0.16 \\
O R=0.74\end{array}$ \\
\hline
\end{tabular}

TE - expander; I - permanent implant; AR autologous reconstruction; RT - radiotherapy; OR - odds ratio; TE/I -> RT - first immediate reconstruction with expander/implant, followed by radiotherapy; AR $\rightarrow$ RT - first immediate autologous reconstruction, followed by radiotherapy; RT -> TE/l - radiotherapy during primary oncological treatment followed by delayed reconstruction with an implant; RT -> AR - radiotherapy during primary oncological treatment followed by delayed autologous reconstruction; TE -> RT -> I - 2-stage immediate reconstruction with radiotherapy onto the expander, followed by exchange into permanent implant; TE - $>R T$ - $>$ AR - 2-stage immediate reconstruction with radiotherapy onto the expander, and in the second stage - autologous reconstruction; I -> RT - 1-stage immediate reconstruction with radiotherapy onto the permanent implant

Table II. The summary of the risk of reconstruction failure on the basis of publications presented in table I $[11,23,48,51-58]$

Type of breast reconstruction with radiotherapy

immediate autologous breast reconstruction followed by radiotherapy

delayed autologous breast reconstruction (following previous radiotherapy)

immediate breast reconstruction with an implant, 1- or 2-stages, followed by radiotherapy onto

the expander or permanent implant

delayed breast reconstruction with an implant, 1- or 2-stages, (following previous radiotherapy)
The rate of implant / flap loss

$0-4.4 \%$

$1.8-7 \%$

$4.5-37 \%$, mainly about $20 \%$

$37-56 \%$ 
a given oncological centre (microvascular anastomoses) and other advantages and disadvantages of specific reconstruction methods. Table III presents a comparison of the benefits and drawbacks of reconstruction with the use of native tissues and implants.

An advantage of an autologous reconstruction is the natural look of the breasts, natural contours and inframammary fold, the natural position of the nipple-areolar complex, a lower rate of complications and increased patient satisfaction with the surgery followed by radiotherapy after long-term follow-up [13, 14, 53, 59, 63]. The downsides of autologous surgeries comprise:

- more extensive type of surgery,

- the level of technical difficulty,

- frequent numerous stages of surgery,

- more pain,

- requirement of a surgical team performing microvascular anastomoses,

- longer recovery period,

- possible complications of the donor site and reconstruction site,

- it is a more expensive procedure than implant reconstruction; and in the case of reconstruction failure, there is little chance of salvage surgery with the use of the patient's own tissues $[15,31,33,60]$.

As opposed to autologous reconstructions, the greatest benefits in the use of prostheses is the shorter treatment time, the immediate treatment effect as perceived by the patients, lower treatment costs and the possibility to use native tissues in the salvage surgery after the loss of the implant [13, 16, 49].

In 2019, after a meeting of the expert panel from 20 countries of the Oncoplastic Breast Consortium (OPBC) [64] the most significant issues which required an urgent solution in oncoplastic surgery with radiotherapy were published. The experts believe that currently the decision about the type of breast reconstruction depends more on the doctor than on the patient. That is why studies of the values of specific reconstruction methods with radiotherapy should be performed, taking into consideration the point of view and feelings of the patients. The results of these studies might help patients in the selection of the most beneficial procedure methods. Moreover, currently the following clinical studies with randomisation have been carried out: Primary Radiotherapy And DIEP flAp Reconstruction Trial (PRADA), DBCG RT Recon Trial, and PREPEC OPBC-02 studies, which are hoped to solve the presented problems with breast reconstruction and radiotherapy [65].

\section{Conclusions}

On the basis of the presented literature, it can be concluded that in the setting of postmastectomy radiotherapy, immediate autolgous breast reconstruction gives fewer complications and guarantees a better quality of life than immediate implant-based reconstruction (both prepectoral and subpectoral). Hence immediate autologous reconstruction really should be one of the available reconstructive options in selected oncological centres. The individual choice of the breast reconstructive method still remains a subject of debate as each of the reconstructive methods has its advantages and disadvantages.

A still very short follow-up period after breast reconstruction performed with the new techniques and a relatively high rate of complications after reconstructions with radiotherapy result in the fact that each patient opting for breast reconstruction should be advised, at the very beginning of their oncological treatment, about the advantages and disadvantages and complication rate in the case of specific reconstructive methods.

The above literature overview and conclusions refer solely to breast reconstructions in patients undergoing radiotherapy.

Table III. The comparison of immediate breast reconstructions with native tissues (autologous) and with synthetic material (implant-based, alloplastic)

\begin{tabular}{|c|c|c|}
\hline & Autologous reconstructions & Alloplastic reconstructions \\
\hline pros & $\begin{array}{l}\text { - preservation of the natural look and contour of the breasts, } \\
\text { natural inframammary fold and natural position of the nipple- } \\
\text {-areolar complex, } \\
\text { - scars are less visible with the progress of time, } \\
\text { - larger patient satisfaction in case of radiotherapy, } \\
\text { - reduction of the excess fat tissue from abdominal integuments } \\
\text { (TRAM) - donor site, } \\
\text { - lower rate of complications following radiotherapy }\end{array}$ & $\begin{array}{l}\text { - technically simpler procedure, } \\
\text { - does not require the ability to make microvascular anastomoses, } \\
\text { - } \text { shorter treatment period, } \\
\text { - } \text { shorter recovery time, } \\
\text { - fewer complaints, } \\
\text { - immediate treatment effect as perceived by the patient, } \\
\text { - lower treatment costs, } \\
\text { - in the case of implant loss it is possible to make a salvage } \\
\text { surgery with the use of patient's native tissues }\end{array}$ \\
\hline cons & $\begin{array}{l}\text { - more extensive and more difficult surgery, often performed in } \\
\text { - } \text { requires the ability to make microvascular anastomoses, } \\
\text { - more painful surgery, } \\
\text { - may lead to complications in the donor and reconstruction site, } \\
\text { - longer hospital stay and recovery, } \\
\text { - more expensive than implant reconstruction, } \\
\text { - in case of failure it is not possible to make a salvage surgery with } \\
\text { native tissues }\end{array}$ & $\begin{array}{l}\text { - } \text { significantly larger rate of complications following radiotherapy, } \\
\text { - unnatural look of the breasts, } \\
\text { the autologous reconstruction followed by radiotherapy, } \\
\text { - lower patient satisfaction with the procedure followed by } \\
\text { radiotherapy }\end{array}$ \\
\hline
\end{tabular}


In breast cancer patients who do not require adjuvant irradiation, the indications for specific reconstruction techniques and complication rates differ from those presented in this paper.

\section{Conflict of interest: none declared}

\section{Anna Niwińska}

Maria Sklodowska-Curie National Research Institute of Oncology Department of Breast Cancer and Reconstructive Surgery

ul. Roentgena 5

02-781 Warszawa, Poland

e-mail:annaniwinska@gmail.com

Received: 20 Sep 2021

Accepted: 22 Sep 2021

\section{References}

1. Sekiguchi K, Kawamori J, Yamauchi H. Breast reconstruction and postmastectomy radiotherapy: complications by type and timing and other problems in radiation oncology. Breast Cancer. 2017; 24(4): 511-520, doi: 10.1007/s12282-017-0754-3, indexed in Pubmed: 28108966.

2. Cardoso F, Kyriakides S, Ohno S, et al. ESMO Guidelines Committee. Electronic address: clinicalguidelines@esmo.org. Early breast cancer: ESMO Clinical Practice Guidelines for diagnosis, treatment and follow-upt. Ann Oncol. 2019; 30(8): 1194-1220, doi: 10.1093/annonc/mdz173, indexed in Pubmed: 31161190.

3. Burstein HJ, Curigliano G, Loibl S, et al. Members of the St. Gallen International Consensus Panel on the Primary Therapy of Early Breast Cancer 2019. Estimating the benefits of therapy for early-stage breast cancer: the St. Gallen International Consensus Guidelines for the primary therapy of early breast cancer 2019. Ann Oncol. 2019; 30(10): 1541-1557, doi: 10.1093/annonc/mdz235, indexed in Pubmed: 31373601.

4. Jassem J, Krzakowski M, Bobek-Billewicz B, et al. Breast cancer. Oncol Clin Pract. 2020; 16(5): 207-260, doi: 10.5603/OCP.2020.0038.

5. Kappos EA, WeberWP, de Boniface J, et al. Immediate Breast Reconstruction. Breast Care (Basel). 2020; 15(2): 188-191, doi: 10.1159/000505176, indexed in Pubmed: 32398989.

6. Wagner RD, Braun TL, Zhu H, et al. A systematic review of complications in prepectoral breast reconstruction. J Plast Reconstr Aesthet Surg. 2019; 72(7): 1051-1059, doi: 10.1016/j.bjps.2019.04.005, indexed in Pubmed: 31076195

7. Vidya R, Berna G, Sbitany $H$, et al. Prepectoral implant-based breast reconstruction: a joint consensus guide from UK, European and USA breast and plastic reconstructive surgeons. Ecancermedicalscience. 2019; 13: 927, doi: 10.3332/ecancer.2019.927, indexed in Pubmed: 31281424.

8. Sbitany H, Gomez-Sanchez C, Piper M, et al. Prepectoral Breast Reconstruction in the Setting of Postmastectomy Radiation Therapy: An Assessment of Clinical Outcomes and Benefits. Plast Reconstr Surg. 2019; 143(1): 10-20, doi: 10.1097/PRS.0000000000005140, indexed in Pubmed: 30589770.

9. Seth AK, Hirsch EM, Fine NA, et al. Utility of acellular dermis-assisted breast reconstruction in the setting of radiation: a comparative analysis. Plast Reconstr Surg. 2012; 130(4): 750-758, doi: 10.1097/ PRS.0b013e318262f009, indexed in Pubmed: 23018687.

10. Sinnott CJ, Persing SM, Pronovost M, et al. Impact of Postmastectomy Radiation Therapy in Prepectoral Versus Subpectoral Implant-Based Breast Reconstruction. Ann Surg Oncol. 2018; 25(10): 2899-2908, doi: 10.1245/s10434-018-6602-7, indexed in Pubmed: 29978367.

11. Thuman JM, Worbowtiz N, Jain A, et al. Impact of Radiation on Implant-Based Breast Reconstruction in Prepectoral Versus Submuscular Planes. Ann Plast Surg. 2021; 86(6S Suppl 5): S560-S566, doi: 10.1097/ SAP.0000000000002882, indexed in Pubmed: 34100813.

12. Yun JH, Diaz R, Orman AG. Breast Reconstruction and Radiation Therapy. Cancer Control. 2018; 25(1): 1073274818795489, doi: 10.1177/1073274818795489, indexed in Pubmed: 30132338.

13. Wilkins EG, Hamill JB, Kim HM, et al. Complications in Postmastectomy Breast Reconstruction: One-year Outcomes of the Mastectomy Reconstruction Outcomes Consortium (MROC) Study. Ann Surg. 2018; 267(1): 164-170, doi: 10.1097/SLA.0000000000002033, indexed in Pubmed: 27906762.
14. Cooke AL, Diaz-Abele J, Hayakawa T, et al. Radiation Therapy Versus No Radiation Therapy to the Neo-breast Following Skin-Sparing Mastectomy and Immediate Autologous Free Flap Reconstruction for Breast Cancer: Patient-Reported and Surgical Outcomes at 1 Year-A Mastectomy Reconstruction Outcomes Consortium (MROC) Substudy. Int J Radiat Oncol Biol Phys. 2017; 99(1): 165-172, doi: 10.1016/j.jrobp.2017.05.001, indexed in Pubmed: 28816143.

15. Kaidar-Person O, Hermann N, Poortmans $P$, et al. A multidisciplinary approach for autologous breast reconstruction: A narrative (re)view for better management. Radiother Oncol. 2021; 157: 263-271, doi: 10.1016/j.radonc.2021.01.036, indexed in Pubmed: 33582192.

16. Towpik E. Postmastectomy breast reconstruction: 15 years of experiences of the warsaw cancer Center. Nowotwory Journal Of Oncology. 2000; 50(5): 529-535.

17. Mazur S, Nagadowska M, Chmielewski R, et al. Postoperative complications and risk of recurrence after skin sparing mastectomy and immediate reconstruction with autologous tissues: 9-year experience. Nowotwory Journal of Oncology. 2009; 59(6): 436-441.

18. Maciejewski A, Dobrut M, Szumniak R, et al. The use of perforator free flaps (DIEP, SGAP) in bilateral breast reconstruction after different types of mastectomy. Cases presentation. Nowotwory Journal of Oncology. 2009; 59(4): 274-279.

19. Meattini I, Becherini $C$, Bernini $M$, et al. Breast reconstruction and radiation therapy: An Italian expert Delphi consensus statements and critical review. Cancer Treat Rev. 2021; 99: 102236, doi: 10.1016/j. ctrv.2021.102236, indexed in Pubmed: 34126314.

20. Chen JJ, von Eyben R, Gutkin PM, et al. Development of a Classification Tree to Predict Implant-Based Reconstruction Failure with or without Postmastectomy Radiation Therapy for Breast Cancer. Ann Surg Oncol. 2021; 28(3): 1669-1679, doi: 10.1245/s10434-020-09068-3, indexed in Pubmed: 32875465.

21. Muresan H, Lam G, Cooper BT, et al. Impact of Evolving Radiation Therapy Techniques on Implant-Based Breast Reconstruction. Plast Reconstr Surg. 2017; 139(6): 1232e-1239e, doi: 10.1097/PRS.0000000000003341, indexed in Pubmed: 28538549.

22. Anker CJ, Hymas RV, Ahluwalia R, et al. The Effect of Radiation on Complication Rates and Patient Satisfaction in Breast Reconstruction using Temporary Tissue Expanders and Permanent Implants. Breast J. 2015; 21(3): 233-240, doi: 10.1111/tbj.12395, indexed in Pubmed: 25772601.

23. Ricci JA, Epstein S, Momoh AO, et al. A meta-analysis of implant-based breast reconstruction and timing of adjuvant radiation therapy. J Surg Res. 2017; 218: 108-116, doi: 10.1016/j.jss.2017.05.072, indexed in Pubmed: 28985836.

24. Fowble B, Park C, Wang F, et al. Rates of Reconstruction Failure in Patients Undergoing Immediate Reconstruction With Tissue Expanders and/or Implants and Postmastectomy Radiation Therapy. Int J Radiat Oncol Biol Phys. 2015; 92(3): 634-641, doi: 10.1016/j.ijrobp.2015.02.031, indexed in Pubmed: 25936815.

25. Nahabedian MY, Tsangaris T, Momen B, et al. Infectious complications following breast reconstruction with expanders and implants. Plast Reconstr Surg. 2003; 112(2): 467-476, doi: 10.1097/01. PRS.0000070727.02992.54, indexed in Pubmed: 12900604.

26. Christante D, Pommier SJ, Diggs BS, et al. Using complications associated with postmastectomy radiation and immediate breast reconstruction to improve surgical decision making. Arch Surg. 2010; 145(9): 873-878, doi: 10.1001/archsurg.2010.170, indexed in Pubmed: 20855758.

27. Chang DW, Barnea Y, Robb GL. Effects of an autologous flap combined with an implant for breast reconstruction: an evaluation of 1000 consecutive reconstructions of previously irradiated breasts. Plast Reconstr Surg. 2008; 122(2): 356-362, doi: 10.1097/PRS.0b013e31817d6303, indexed in Pubmed: 18626350.

28. Ascherman JA, Hanasono MM, Newman MI, et al. Implant reconstruction in breast cancer patients treated with radiation therapy. Plast Reconstr Surg. 2006; 117(2): 359-365, doi: 10.1097/01.prs.0000201478.64877.87, indexed in Pubmed: 16462313.

29. Vieira RA, Ribeiro LM, Carrara GF, et al. Effectiveness and Safety of Implant-Based Breast Reconstruction in Locally Advanced Breast Carcinoma: A Matched Case-Control Study. Breast Care (Basel). 2019; 14(4): 200-210, doi: 10.1159/000496429, indexed in Pubmed: 31558894.

30. Billig J, Jagsi R, Qi Ji, et al. Should Immediate Autologous Breast Reconstruction Be Considered in Women Who Require Postmastectomy Radiation Therapy? A Prospective Analysis of Outcomes. Plast Reconstr Surg. 2017; 139(6): 1279-1288, doi: 10.1097/PRS.0000000000003331, indexed in Pubmed: 28198770. 
31. Rochlin DH, Jeong AR, Goldberg $\mathrm{L}$, et al. Postmastectomy radiation therapy and immediate autologous breast reconstruction: integrating perspectives from surgical oncology, radiation oncology, and plastic and reconstructive surgery. J Surg Oncol. 2015; 111(3): 251-257, doi: 10.1002/jso.23804, indexed in Pubmed: 25339608.

32. Spear SL, Ducic I, Low M, et al. The effect of radiation on pedicled TRAM flap breast reconstruction: outcomes and implications. Plast Reconstr Surg. 2005; 115(1): 84-95, indexed in Pubmed: 15622237.

33. Kelley BP, Ahmed R, Kidwell KM, et al. A systematic review of morbidity associated with autologous breast reconstruction before and after exposure to radiotherapy: are current practices ideal? Ann Surg Oncol. 2014; 21(5): 1732-1738, doi: 10.1245/s10434-014-3494-z, indexed in Pubmed: 24473643.

34. Spear SL, Onyewu C. Staged breast reconstruction with saline-filled implants in the irradiated breast: recent trends and therapeutic implications. Plast Reconstr Surg. 2000; 105(3): 930-942, doi: 10.1097/00006534-200003000-00016, indexed in Pubmed: 10724252.

35. Nava MB, Pennati AE, Lozza L, et al. Outcome of different timings of radiotherapy in implant-based breast reconstructions. Plast Reconstr Surg. 2011; 128(2): 353-359, doi: 10.1097/PRS.0b013e31821e6c10, indexed in Pubmed: 21788827.

36. Cordeiro PG, Albornoz CR, McCormick B, et al. What Is the Optimum Timing of Postmastectomy Radiotherapy in Two-Stage Prosthetic Reconstruction: Radiation to the Tissue Expander or Permanent Implant? Plast Reconstr Surg. 2015; 135(6): 1509-1517, doi: 10.1097/ PRS.0000000000001278, indexed in Pubmed: 25742523.

37. Ho AL, Bovill ES, Macadam SA, et al. Postmastectomy radiation therapy after immediate two-stage tissue expander/implant breast reconstruction: a University of British Columbia perspective. Plast Reconstr Surg. 2014; 134(1): 1e-110e, doi: 10.1097/PRS.0000000000000292, indexed in Pubmed: 25028850.

38. Anderson PR, Freedman G, Nicolaou N, et al. Postmastectomy chest wall radiation to a temporary tissue expander or permanent breast implant--is there a difference in complication rates? Int J Radiat Oncol Biol Phys. 2009; 74(1): 81-85, doi: 10.1016/j.jrobp.2008.06.1940, indexed in Pubmed: 18823714

39. Pu Y, Mao TC, Zhang YM, et al. The role of postmastectomy radiation therapy in patients with immediate prosthetic breast reconstruction: A meta-analysis. Medicine (Baltimore). 2018; 97(6): e9548, doi: 10.1097/ MD.0000000000009548, indexed in Pubmed: 29419662.

40. Hong WJ, Zhang GY, Chen CL, et al. The Effect of Previous Irradiation for Patients With Prosthetic Breast Reconstruction: A Meta-Analysis. Aesthet Surg J. 2021; 41(7): NP748-NP757, doi: 10.1093/asj/sjaa372, indexed in Pubmed: 33621335.

41. Li L, Su Y, Xiu B, et al. Comparison of prepectoral and subpectoral breast reconstruction after mastectomies: A systematic review and meta analysis. Eur J Surg Oncol. 2019; 45(9): 1542-1550, doi: 10.1016/j. ejso.2019.05.015, indexed in Pubmed: 31256950.

42. Abbate $\mathrm{O}$, Rosado N, Sobti N, et al. Meta-analysis of prepectoral implant-based breast reconstruction: guide to patient selection and current outcomes. Breast Cancer Res Treat. 2020; 182(3): 543-554, doi: 10.1007/ s10549-020-05722-2, indexed in Pubmed: 32514624

43. Nahabedian MY, Cocilovo C. Two-Stage Prosthetic Breast Reconstruction: A Comparison Between Prepectoral and Partial Subpectoral Techniques. Plast Reconstr Surg. 2017; 140(6S Prepectoral Breast Reconstruction): 22S-30S, doi: 10.1097/PRS.0000000000004047, indexed in Pubmed: 29166344.

44. Patel AA, Arquette CP, Yesantharao PS, et al. Examining the Effects of Postmastectomy Radiation Therapy in Prepectoral Versus Subpectoral Autologous Breast Reconstruction. Ann Plast Surg. 2021; 86(5S Suppl 3): S390-S394, doi: 10.1097/SAP.0000000000002762, indexed in Pubmed: 33976068

45. Dave RV, Vucicevic A, Barrett E, et al. Risk factors for complications and implant loss after prepectoral implant-based immediate breast reconstruction: medium-term outcomes in a prospective cohort. Br J Surg. 2021; 108(5): 534-541, doi: 10.1002/bjs.11964, indexed in Pubmed: 34043774

46. Chung SY, Chang JS, Shin KH, et al. Impact of radiation dose on complications among women with breast cancer who underwent breast reconstruction and post-mastectomy radiotherapy: A multi-institutional validation study. Breast. 2021; 56: 7-13, doi: 10.1016/j. breast.2021.01.003, indexed in Pubmed: 33517043.

47. Barry M, Kell MR. Radiotherapy and breast reconstruction: a meta-analysis. Breast Cancer Res Treat. 2011; 127(1): 15-22, doi: 10.1007/ s10549-011-1401-x, indexed in Pubmed: 21336948.
48. O'Donnell JPM, Murphy D, Ryan ÉJ, et al. Optimal reconstructive strategies in the setting of post-mastectomy radiotherapy - A systematic review and network meta-analysis. Eur J Surg Oncol. 2021 [Epub ahead of print], doi: 10.1016/j.ejso.2021.07.001, indexed in Pubmed: 34301444 .

49. Huang $Y$, Sanz J, Rodríguez $N$, et al. Effects of radiation on toxicity, complications, revision surgery and aesthetic outcomes in breast reconstruction: An argument about timing and techniques. J Plast Reconstr Aesthet Surg. 2021 [Epub ahead of print], doi: 10.1016/j. bjps.2021.05.027, indexed in Pubmed: 34229955.

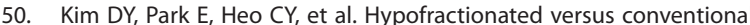
fractionated radiotherapy for breast cancer in patients with reconstructed breast: Toxicity analysis. Breast. 2021; 55: 37-44, doi: 10.1016/j. breast.2020.11.020, indexed in Pubmed: 33316582.

51. Tanos G, Prousskaia E, Chow W, et al. Locally Advanced Breast Cancer: Autologous Versus Implant-based Reconstruction. Plast Reconstr Surg Glob Open. 2016; 4(2): e622, doi: 10.1097/GOX.0000000000000598, indexed in Pubmed: 27014551.

52. Chetta MD, Aliu O, Zhong $L$, et al. Reconstruction of the Irradiated Breast: A National Claims-Based Assessment of Postoperative Morbidity. Plast Reconstr Surg. 2017; 139(4): 783-792, doi: 10.1097/ PRS.0000000000003168, indexed in Pubmed: 28002254.

53. Jagsi R, Momoh AO, Qi Ji, et al. Impact of Radiotherapy on Complications and Patient-Reported Outcomes After Breast Reconstruction. J Natl Cancer Inst. 2018; 110(2), doi: 10.1093/jnci/djx148, indexed in Pubmed: 28954300.

54. Manyam BV, Shah C, Woody NM, et al. Long-Term Outcomes After Autologous or Tissue Expander/Implant-Based Breast Reconstruction and Postmastectomy Radiation for Breast Cancer. Pract Radiat Oncol. 2019; 9(6): e497-e505, doi: 10.1016/j.prro.2019.06.008, indexed in Pubmed: 31238166.

55. Reinders FCJ, Young-Afat DA, Batenburg MCT, et al. Higher reconstruction failure and less patient-reported satisfaction after post mastectomy radiotherapy with immediate implant-based breast reconstruction compared to immediate autologous breast reconstruction. Breast Cancer. 2020; 27(3): 435-444, doi: 10.1007/s12282-019-01036-4, indexed in Pubmed: 31858435.

56. Naoum GE, Salama L, Niemierko A, et al. Single Stage Direct-to-Implant Breast Reconstruction Has Lower Complication Rates Than Tissue Expander and Implant and Comparable Rates to Autologous Reconstruction in Patients Receiving Postmastectomy Radiation. Int J Radiat Oncol Biol Phys. 2020; 106(3): 514-524, doi: 10.1016/j. ijrobp.2019.11.008, indexed in Pubmed: 31756414.

57. Hershenhouse KS, Bick K, Shauly O, et al.„,Systematic review and meta-analysis of immediate versus delayed autologous breast reconstruction in the setting of post-mastectomy adjuvant radiation therapy". J Plast Reconstr Aesthet Surg. 2021; 74(5): 931-944, doi: 10.1016/j. bjps.2020.11.027, indexed in Pubmed: 33423976.

58. Heiman AJ, Gabbireddy SR, Kotamarti VS, et al. A Meta-Analysis of Autologous Microsurgical Breast Reconstruction and Timing of Adjuvant Radiation Therapy. J Reconstr Microsurg. 2021; 37(4): 336-345, doi: 10.1055/s-0040-1716846, indexed in Pubmed: 32957153.

59. Santosa KB, Qi Ji, Kim HM, et al. Long-term Patient-Reported Outcomes in Postmastectomy Breast Reconstruction. JAMA Surg. 2018; 153(10): 891-899, doi: 10.1001/jamasurg.2018.1677, indexed in Pubmed: 29926096.

60. Miseré RMI, van Kuijk SMj, Claassens EL, et al. Breast-related and body-related quality of life following autologous breast reconstruction is superior to implant-based breast reconstruction - A long-term follow-up study. Breast. 2021;59: 176-182, doi: 10.1016/j.breast.2021.07.003, indexed in Pubmed: 34271290.

61. Nelson JA, Allen RJ, Polanco T, et al. Long-term Patient-reported Outcomes Following Postmastectomy Breast Reconstruction: An 8-year Examination of 3268 Patients. Ann Surg. 2019; 270(3): 473-483, doi: 10.1097/SLA.0000000000003467, indexed in Pubmed: 31356276.

62. Toyserkani NM, Jørgensen MG, Tabatabaeifar S, et al. Autologous versus implant-based breast reconstruction: $A$ systematic review and meta-analysis of Breast-Q patient-reported outcomes. J Plast Reconstr Aesthet Surg. 2020; 73(2): 278-285, doi: 10.1016/j.bjps.2019.09.040, indexed in Pubmed: 31711862.

63. Craig ES, Lentz $R$, Srinivasa $D$, et al. Three-dimensional Analysis of How Radiation Affects Deep Inferior Epigastric Perforator (DIEP) Flap Volume, Projection, and Position in Breast Cancer Reconstruction. Ann Plast Surg. 2018; 81(2): 235-239, doi: 10.1097/SAP.0000000000001462, indexed in Pubmed: 29794501.

64. Weber WP, Morrow M, Boniface Jde, et al. Oncoplastic Breast Consortium. Knowledge gaps in oncoplastic breast surgery. Lancet Oncol. 
2020;21(8): e375-e385, doi: 10.1016/S1470-2045(20)30084-X, indexed in Pubmed: 32758475.

65. Kaidar-Person O, Offersen BV, Boersma LJ, et al. A multidisciplinary view of mastectomy and breast reconstruction: Understanding the challenges. Breast. 2021; 56: 42-52, doi: 10.1016/j.breast.2021.02.004, indexed in Pubmed: 33610903. 